\title{
E-Cigarettes for Smoking Cessation: Why do Users Continue with E-Cigarettes?
}

\author{
A.L.S. Foong ${ }^{1} \&$ M.Y.Y. Lai $^{2}$ \\ ${ }^{1}$ College of Health \& Medicine, University of Tasmania, Rozelle Campus, Australia \\ ${ }^{2}$ International Medical University, Kuala Lumpur, Malaysia \\ Correspondence: A.L.S. Foong. E-mail: andfoong@gmail.com
}

Received: June 11, 2018 Accepted: October 29, $2018 \quad$ Online Published: November 29, 2018

doi:10.5539/ass.v14n12p156

URL: https://doi.org/10.5539/ass.v14n12p156

\begin{abstract}
The advent of e-cigarettes (vaping) well over a decade ago, was welcomed as a tool to aid cigarette smoking cessation. Whilst it has served its aims for many, there remains several who switched to vaping but did not cease cigarette smoking. They also continued with vaping behaviours. The aim of this study is to identify and gain a better understanding of why their vaping behaviours continue. With that in mind, a qualitative study with focus groups was undertaken. A purposive convenience sample of 17 participants who are patrons of 3 vaping centres in the city of Kuala Lumpur were recruited. Four focus groups were formed from the sample of 17 participants. Data derived from the focus groups identified seven themes which emerged as motivating factors for continued vaping behaviours. They comprised of social acceptance; attraction to flavours; a sense of accomplishment; financial savings; convenience compared to smoking; perceived low health risk; and behavioural substitution. Findings suggest that vaping behaviours could be conceptualised by Choice Theory based on psychosocial needs of survival, achievement, love and belonging, freedom and fun. They highlight the role of psychosocial factors that could be considered of importance in informing policy and practices for smoking cessation programmes and activities.
\end{abstract}

Keywords: e-cigarettes, smoking cessation, vaping behaviours, psychosocial; young adults, qualitative, Malaysia

\section{Introduction}

Since its initial commercialisation in 2003, the popularity of e-cigarettes has increased exponentially with impacts on the lives of conventional cigarette smokers who wished to quit (Foulds, Veldheer \& Berg, 2011). It provided smokers an alternative which many considered, a healthier nicotine delivery system (Wagener, Siegel \& Borrelli, 2012; Pepper \& Brewer, 2014). Its proliferation is evidenced by a growth of over 5000 percent generated from the phrase "electronic cigarette" on Google. Also, a study on Google search queries on e-cigarettes from 2008 to 2010 found it surpassed the popularity of nicotine replacement therapies (Ayers, Ribisi, \& Brownstein, 2011). E-cigarette use, or vaping (as it is now more commonly known, and users referred to as vapers) is marketed as a smoking cessation aid. Evidence suggests that e-cigarette use can perform to a similar extent if not better than nicotine replacement therapies in terms of reducing smoking behaviour (Barbeau, Burda $\&$ Siegel, 2013; Orr \& Asal, 2014). The literature on effectiveness of nicotine replacement therapy has also been mixed and not without issues and controversy (Moore et al., 2009; Alpert, Connolly \& Biener, 2012; Hughes et al., 2012). It is worth noting that efficiency rates between e-cigarette generations can differ significantly. The latest third generation e-cigarette, for example, has more advanced hardware that allows control of power, as well as fail-safes to protect against battery issues (Brown \& Cheng 2014).

Figures from the United Kingdom health charity Action on Smoking and Health (ASH, 2014) indicated e-cigarette usage in Britain tripled over a two-year period from 700,000 in 2012 to 2.1 million in 2014. Figures from Gravely et al. (2014) reported around 62 percent of the population in Malaysia are aware of e-cigarettes; 19 percent have tried it; and 14 percent currently use it. Studies in Malaysia indicate that 82 percent of the smoking population consider e-cigarettes as a "positive alternative to cigarettes (Davendralingam \& Erwin, 2015), with 88 percent of a sample of 429 attributing their use as a means to help stop their smoking addiction (Wong et al., 2016). However, it appears that having switched to vaping with the initial aim as an aid to cease smoking, many continue with their vaping behaviour (Palazzolo, 2013, Orr \& Asal, 2014). This raises the question of what the 
motivating factors are, that drive continued e-cigarette use in a country like Malaysia where the usage is reported to be the second highest in the world (Winn, 2015). Review of literature suggests multiple factors reinforce usage (Elkalmi et al., 2016; Wong et al., 2016; Pepper \& Brewer, 2014). These include behavioural substitution, social acceptance, a perception of reduced health risk, sense of accomplishment, financial savings, attraction to flavours, and convenience.

\section{Literature Review}

In a survey of 179 e-cigarette users in Poland, 93 percent of participants believed e-cigarettes to be addictive but not as much as conventional cigarettes (Goniewicz, Lingas, \& Hajek, 2013). The frequency of vaping was also reported to be higher in a day when compared to cigarette smoking, possibly, due to e-cigarettes being more socially acceptable compared to cigarettes (Vansickel, Cobb, Weaver, \& Eissenberg, 2010). However, there are variations to this picture with a systematic review of the literature suggesting the belief in the use of e-cigarettes as a substitute for smoking in smoking-restricted areas varied between countries (Pepper \& Brewer, 2014). It reinforces the assertion of smoking cessation being a complex and dynamic process in need of broader considerations (Yeh, Bullen \& Glantz, 2016). In countries such as Bahrain and Singapore, the sale and distribution of e-cigarettes are banned (Davendralingam \& Erwin, 2015). Further studies may well shed light on the broader issues impacting the prevalence of e-cigarette use. Retailers of vape shops categorized four types of people who use e-cigarettes. Those who wish to stop smoking, those who wish to continue smoking in public places, those who want to smoke without the health risks of cigarettes, and those who wish to save money (Rafter, 2008).

Findings on the health effects of e-cigarettes are mixed. Recently, the positive effects of e-cigarettes have been reported when compared to conventional cigarettes, with no risk to human health found in e-cigarette emissions (Abidin, Zulkifli, \& Abidin, 2016), challenging the notion that second-hand vapour is harmful to health. Indeed, the recently released position statement from the American Cancer Society (2018) is positive towards people who choose to use e-cigarettes over other methods of smoking cessation. The positive effects suggested are that e-cigarettes resolved symptoms such as aggressiveness, headaches, cough, as well as providing a "fresh feeling" after vaping (Nik Mohamad, \& Jamshed, 2015). On the other hand, anecdotal reports have suggested some risks from vaping to include those of chest pain and pneumonia (Chen, 2013; Hua, Alfi \& Talbot, 2013). Nevertheless, vapers seem unfazed by such reports and given the primary reason for the use of e-cigarettes to aid smoking cessation it appears that many continue with them, further reinforcing the question of whether there should be other factors that propagate the behaviour (Yeh, Bullen \& Glantz, 2016). In this regard, it is suggested that psychosocial factors may well play a significant role in providing insights into the issue. For instance, young social smokers have been reported to have particular challenges when it comes to smoking cessation (Song \& Ling, 2011), more so for those from higher rather than lower socio-economic positions (Paul et al., 2010). They are also more susceptible to marketing approaches linking smoking to social activities (Ling \& Glantz, 2002). The role of basic human needs from the psychosocial perspective may well provide some insights into motivations for persistent e-cigarettes use. In that respect, Glasser's Choice Theory (1998) suggested five basic needs driving the behaviours. They are survival in society; acceptance/sense of belonging; achievement; freedom; and fun. The extent to which the theory could provide insights into psychosocial explanations for continued vaping behaviours could be useful in contributing to the smoking cessation narrative, including further research and informing intervention strategies.

It has been reported that 57 percent of participants quoted "cheaper than smoking" as their reason for use (Etter $\&$ Bullen, 2011). This economic factor was also indicated by a study in Malaysia with the deduction that vapers could be maintaining usage of their e-cigarettes to satisfy their oral habit without incurring financial strain on themselves (Davendralingam \& Erwin, 2015).

Vaping can be seen as a tool for social acceptance with multifacets. The ability of the e-cigarette to change the self-identity of a "smoker" to a more socially acceptable "vaper", helps ease transition to smoking abstinence (Barbeau, Burda, \& Siegel, 2013). This identity grants privileges for participation in online forums and social situations, where information and social support are shared amongst vapers (McQueen, Tower, \& Sumner, 2011). However, the same boon that helps smokers move towards abstinence and discussion may well be a double-edged sword in a sense that it may be maintaining their usage.

Another aspect of continued use could be the sense of accomplishment acquired when customising devices. With the influx of e-cigarettes on the market, consumers must be skilled and knowledgeable to utilize them. The learning curve of e-cigarette usage is such that experienced vapers gained self-satisfaction as they worked towards customisation for their own preferences (McQueen, Tower, \& Sumner, 2011). With the effort of learning 
the many facets of device customisation, comes the probability of users displaying their proficiency to others, and with it, the sense of self-accomplishment - further propagating customisation and continued vaping behaviours (Measham, O'Brien, \& Turnbull, 2016). This is similar to the report that adolescents' usage of such devices was a way to seem "cool" and to show off to their peers (Hammal \& Finegan, 2016), propagating their sense of belonging and acceptance. The next logical instinct after achieving the survival goal (decreasing the physical and financial stresses due to the substitution of smoking with vaping) would be to further integrate oneself into the larger society, to achieve the sense of belonging.

The seemingly unlimited range of flavours on the market may also be a prominent factor in maintaining use, providing a sense of freedom of expression and enjoyment. Flavours range from tobacco to fruits, beverages, sweets and many others (Farsalinos et al., 2013). Furthermore, it was found that decreased variability of flavours significantly lessened the enjoyment of an individual's vaping experience (Farsalinos et al., 2013), suggesting that the availability of flavours enhances the vaping experience. The wide range of flavours provide the platform to experiment with numerous flavours and mixtures. In particular, young adults tend to be attracted towards the activity of combining flavours (Measham, O'Brien, \& Turnbull, 2016), further increasing the customisability of the product.

Clearly, vaping behaviours have multifaceted pespectives that may be serving as reinforcers or propagaters. Given the background a study to depict the psychosocial landscape would be helpful in presenting a picture to contribute to the smoking cessation narrative and help with strategies for cessation.

\section{Aim of study}

To explore reasons why those who are using e-cigarettes to help with smoking cessation continue with e-cigarettes.

\section{Methods}

A qualitative research design was adopted for this study as it would enable a deeper understanding of lesser-known phenomena (Speziale, Streubert, \& Carpenter, 2011). Focus groups were used to elicit data from a sample of users of e-cigarettes who frequented vape cafes over a one month period in 2016. Given the need to gain data from a specific target group, purposeful convenience and snowball sampling was utilized in this study.

\subsection{Participants Inclusion Criteria}

1. Must be competent in the English language.

2. Participants must be at least 18 years old.

3. Participants must be a current user of e-cigarettes for at least 1 year.

4. Must own at least one third-generation e-cigarette.

\subsection{Sample Size}

A total of 17 participants who fulfilled the inclusion criteria were recruited for this study with four to six participants per focus group session. Four focus groups were undertaken for this study.

\subsection{Materials}

An audio recording device was used to record raw data for analysis. A demographics survey was used to document age, occupation, level of education, inclusion criteria, experience of vaping cessation, duration of smoking (current smokers), and intention to stop smoking and/or vaping. A consent form was used to ensure participants' signed consent to participate in the study.

\subsection{Procedure}

Approval to conduct this study was first obtained from the Research Ethics Committee at a private university [BPS I-1/14(04)2016]. Participants were then recruited from various vape cafes in Kuala Lumpur as well as by snowballing. The purpose of the study was explained and participants were given opportunities to seek clarifications before signed consent was obtained. After that, participants were given demographics survey to be completed and verbal consent obtained before proceeding. Focus group sessions were audio-recorded. Their durations varied from 20-45 minutes until data saturation points were reached. Data obtained was then transcribed and analysed using thematic analysis.

\section{Data Analysis}

All data were transcribed ad verbatim following completion of focus groups interviews. Data were first analysed through conventional content analysis and coded for categorization. Thematic analysis was undertaken to 
identify meaningful themes and patterns arising from the transcripts (Glesne, 2011).

Table 1. Participant demographics information

\begin{tabular}{|c|c|c|c|c|c|c|c|c|c|}
\hline Age & Occupation & Education & $\begin{array}{l}\text { Vaping } \\
\text { duration }\end{array}$ & $\begin{array}{l}\text { Intention } \\
\text { to stop } \\
\text { vaping }\end{array}$ & $\begin{array}{c}\text { Mods } \\
\text { owned }\end{array}$ & $\begin{array}{l}\text { Tanks } \\
\text { owned }\end{array}$ & $\begin{array}{c}\text { Tried to } \\
\text { stop vaping }\end{array}$ & $\begin{array}{l}\text { Smoking Duration } \\
\text { (dual-users) }\end{array}$ & $\begin{array}{l}\text { Intention } \\
\text { to stop } \\
\text { smoking }\end{array}$ \\
\hline 21 & Student & Degree & 24 months & No & 3 & 6 & No & 6 years & yes \\
\hline 20 & Student & Diploma & 12 months & No & 3 & 2 & No & Non-dual user & \\
\hline 22 & Student & Degree & 36 months & No & 10 & 10 & No & Occasional & No \\
\hline 26 & Salesman & Degree & 12 months & Yes & 1 & 3 & Yes & 9 years & Yes \\
\hline 22 & Student & Diploma & 12 months & Yes & 2 & 2 & Yes & 4 years & No \\
\hline 20 & Student & Foundation & 13 months & Yes & 1 & 1 & No & 18 months & Yes \\
\hline 21 & Student & Degree & 13 months & Yes & 1 & 1 & Yes & 36 months & Yes \\
\hline 22 & Student & Degree & 13 months & Maybe & 1 & 1 & Yes & 19 months & Yes \\
\hline 23 & Student & Diploma & 18 months & No & 1 & 1 & Yes & 24 months & Yes \\
\hline 23 & Student & Degree & 12 months & Yes & 1 & 1 & No & Non-dual user & Stopped \\
\hline 22 & Student & Degree & 12 months & Yes & 1 & 1 & Yes & Non-dual user & Stopped \\
\hline 23 & Barista & Degree & 13 months & Maybe & 3 & 4 & Yes & Non-dual user & Stopped \\
\hline 20 & Student & Degree & 13 months & No & 1 & 1 & No & 20 months & No \\
\hline 20 & Student & Diploma & 12 months & Maybe & 1 & 1 & Yes & 24 months & Yes \\
\hline 21 & Student & Degree & 13 months & Yes & 1 & 1 & Yes & Non-dual user & Stopped \\
\hline 30 & Marketing & Degree & 26 months & No & 4 & 3 & No & Non-dual user & Stopped \\
\hline 21 & Student & Diploma & 13 months & Yes & 2 & 3 & Yes & Non-dual user & Stopped \\
\hline
\end{tabular}

Table 1 Demographics information of participants in the study, as shown in the table above, most participants in this study were young adult students with degree level education.

\section{Results}

A total of 17 vapers participated in the focus group discussions. Their ages ranged from 20 to 30 years (mean = 22.18). The length of time vaping ranged from 12 to 36 months (mean $=15.07)$. Ten $(59 \%)$ have tried to stop vaping. Six $(35 \%)$ have no plans to stop vaping. The results indicated several factors that were seen as main motivators to continued vaping behaviour. Coding and further categorisation enabled classification of the categories into four main themes, namely, social acceptance; attraction to flavours; sense of accomplishment; and, behavioural substitution

\subsection{Social Acceptance}

\section{Acceptance when in a group of non-smokers}

Participants shared that vaping helps them socially in terms of being accepted within a group of non-smoking friends. Vaping leaves little to no trace of undesirable smell when compared to cigarettes, as indicated by "The stench. For vape you can't really smell it, people don't know that you vape". They prefer the situation where their behaviour of smoking or in this case vaping, can continue without the social repercussions of being shunned by non-smokers. The impression is that, "If you smoke and smell like cigarettes, people will stay away from you. So, when you start vaping and people can't smell it, it's a lot easier to be in a social group"

\section{Acceptance in a group of vapers}

Participants expressed that vaping allows them to feel accepted within a social group of vapers, such as indicated by, "You have that in common with your friends and the people around you", and reinforced by, "When their friends do it, their friends are enjoying it, and they feel like they need to also be a part of that in order to be more in the group". There seemed to be a similarity between participants across interviews about smoking and vaping in terms of using it as a social tool apart from reducing stress. The issue of acceptance was extended by, "sometimes it's a really good way to socialise with people" and, for "some people, it's really hard to interact with them until you smoke with them and suddenly it opens up". The feeling is that "... you can use it to reduce utter silences". In the interviews, a participant likened the social use of cigarettes being transferred into vaping, with the possibility that vaping could be used as a conversational tool where it is the "same thing as smoking I guess. It starts conversations, people ask you "what mods you use" "what flavour this is". Hence, "it can be fun 
as in people with similar interests can come together and talk about this"

\section{Following the trend}

Vaping is seen as a trend, creating a platform for individuals to feel accepted in a group or community by vaping. Thus, driving vaping behaviour so as to be socially accepted is indicated by "they just want to try new things and I don't think they would keep doing that. It's like "... once they've tried, I think they are done, it's like a phase. I would think it's a phase". It seems that ".... Malaysians are always into the trend of vaping and we shisha a lot. So once something new comes out everyone just wants to do it, we just want to follow the trend".

\subsection{Attraction to Flavours}

Participants in all interview groups expressed their interest in e-juice when talking about why they vape. Portrayed in the interviews, was the seemingly enormous range and possibility of flavours which drove their behaviour. When asked about the reasons underlying continued vaping after smoking cessation, responses included, "... one of the reasons is to try more flavours". Another participant describes e-juice available in vaping, as similar to an exciting journey through the unknown. "like what Forest Gump likes to say, life is like a box of chocolates. You never know what you're going to get". There were also comparisons between the flavours of smoking versus vaping: "it's tobacco so you know how it's going to taste. When it comes to vaping it's another level of taste". One participant also said that for custom mixtures of juices, he yearns for the perfect flavour he once experienced by trying many different flavours, until the perfect blend is tasted: "The taste of it, because you can get home-brewed ones, you get that, and next thing you know you can't get that (taste) anymore. You try to look for a substitute, to try different brands, just to try to get back the same taste". It is a clear motivator to continued vaping.

\subsection{Sense of Accomplishment}

Participants expressed a sense of accomplishment and uniqueness when they managed to build a complicated coil. Also, a sense of fulfilment as the coil they built granted them the specific flavour profile they seek for in their e-juice. "You want to feel a bit more unique, just that if anything is wrong, add more air (airflow), or you do something with your coil, it's a bit different you know - you feel unique". It feels good "for people who do like to coil, you know everything that you do you feel good with that sense of competence. That you're able to do things, customize things to your own preference".

Also, it was expressed that e-cigarettes were engineered to be customised. This may be one of the pull factors that make vapers continue their vaping behaviour, such as indicated by "it's been made a tool that you can tinker with and customize", and "it's a customisable product, whether you tinker to get better flavour or more clouds and so on". It can be seen, that vapers obtain satisfaction and are excited to learn about new ways to build, such as "you have to learn it yourself. And then once you start learning then you start playing around then you just find whatever you like". "For me coiling...it's not easy. Not everyone can do it because some people if they really learn it well they can recoil it in different kinds of ways".

There were also conversations which suggested vapers build coils to attain affirmation from others. This was accomplished by taking pictures of their builds and posting them on social media such as Instagram to obtain attention and affirmation. For example, "on Instagram there's this page called "vape porn" and people show off their coils. Their crazy looking ones with different names". "Then they always Snapchat, Instagram, and all that stuff so that people will 'like' it". What is often stated in social media is, "hey, check out this one".

\subsection{Behavioural Substitution}

Discussions in the focus groups highlighted the habit-forming nature of vaping where "it becomes a habit like you need to have it". This sense is reinforced by, "If I work or if I study without vaping or smoking I couldn't do anything, I couldn't process in my brain. Maybe it's just psychological".

A participant expressed that he wished to substitute his smoking behaviour with vaping. It is manifested by the suggestion that the intention to start and continue vaping was due to the urge to substitute the oral behaviour of smoking with vaping - "Vaping to me is like a substitute for smoking, it's an on and off thing. For example, we are trying to make vaping the main thing instead of smoking. So I'm starting small as like, I don't smoke in the car, don't smoke in the house. Things like that so, as it becomes a substitute, eventually it becomes a norm to me, hopefully"

\section{Financial savings}

Participants shared about financial savings they can achieve by vaping compared with smoking. It was discussed that even though getting started with vaping requires a relatively high amount of capital when compared with 
smoking, in the long-term money could be saved by vaping instead of smoking. However, this also suggests that vaping could just be a substitute for smoking behaviour without incurring financial strains. "Maybe because it cut costs, because I am still a smoker, just not as frequent, if you are 'a pack a day' smoker, vaping would significantly cut down the cost".

The financial aspects of vaping appeared to serve as barriers to cessation. This is due to the perception of high investment into vaping that individuals feel the need to make the most out of it. For instance, "it's harder to stop because you've already invested so much money into it". It is somewhat "like a car. You spend so much on the car, you're not just going to drive it around, you want to make it yours, because you spent so much time and effort at maintaining that, so why not just spend a little bit more and make it more personal".

\section{Convenience}

It is more convenient for them to vape rather than to smoke. For example, "you have to keep buying cigarettes. If you buy a bottle (e-juice) you can just like, use it longer than cigarettes". A participant said that if he were to smoke, he had to finish the whole cigarette, which takes a certain amount of time. With vaping, on the other hand, he can vape at any time and stop anytime he likes. "Cigarettes you actually have to wait there and wait for the whole cigarette to finish, while with vaping you can just take it out, turn it on and vape then just turn it off".

Perceived low health risk

A theme that arose was the lack of health risks in terms of vaping when compared to smoking. From the data obtained, it can be deduced that this theme seems to act as an initial motivator for vaping since vapers could continue their behaviour without incurring health risks. "I think it's the perception, the way that vaping is portrayed now is that it is not harmful or it's less harmful than smoking". The thinking is that "I don't have a reason to stop, it's not affecting my health". Furthermore, "... because it's marketed as being less harmful than smoking, so you think that there's no harm to it". So, it is seen as, "... a healthier option because all the research, and experiments they posted on Facebook and stuff shows that in comparison with cigarettes, vape doesn't really affect the lungs".

\section{Discussion}

\subsection{Social Acceptance}

Social acceptance was a prominent theme that emerged from the focus group discussions. It means getting signals from others that you are included in their groups and relationships (Leary, 2010). Such signals satisfy the basic need for belonging (DeWall \& Richman, 2011) which enhances various psychological states of wellbeing such as self-esteem (Williams et al., 2000), evoking various wellbeing enhancing biological responses including hormonal (Maner, Miller, Schmidt \& Eckel, 2008), and activation in brain regions associated with emotive states (Eisenberger, Lieberman \& Williams, 2003; Hillebrandt, Sebastian, Blakemore, 2010) such as for the feel-good factor. The lack of foul tobacco odour from vaping when compared to cigarette smoking, enabled social acceptance to non-smoker groups thus providing opportunities for widening of social circles. Other than that, it was found that participants use vaping behaviour to facilitate conversations with others. This finding provides significant insights into the implications for understanding the dynamics of vaping in Malaysia with its collectivistic culture (Abdullah \& Pedersen, 2003). The collectivistic thinking style that considers the group as more important than the individual (Hofstede, 1984) could serve as an explanation as to why this factor was so prominent. Cultural insights are important considerations for understanding smoking behaviours, for instance, as in China where gifting and sharing of cigarettes are common practice (Kohrman, 2007), and in Bangladeshi society, where tradition and culture served an important role in nurturing and cultivating tobacco smoking contributing to group cohesion and identity (Bush et al., 2003). Similarly, the fundamental psychological need of humans posited by choice theory included the need to form a sense of belonging to significant others (Glasser, 1998; Mottern, 2008). The psychological need to be accepted, coupled with living in a collectivistic culture, may well contribute to the prominence of this theme in Malaysia. Social acceptance and the need to belong are phenomena with major impacts on human behaviour, but the underlying mechanisms to explain their discrete workings remain mysteries for psychological scientists to examine (DeWall \& Bushman, 2011).

\subsection{Attraction to Flavours}

The seemingly endless amount of options in terms of variations of e-juice was found to be driving continued vaping behaviour. Participants expressed enthusiasm and knowledge of variations when it came to the topic of e-juice. The sense of excitement of a participant led him to describe his experiences of trying different e-juices as "like a box of chocolates, you never know what you're going to get". This was a new finding as the literature mostly examined how individuals perceived the selection of e-juice available in the market but not on how 
choices in e-juice were one of the reasons vapers continue their vaping behaviour.

In terms of Malaysia, there is a relatively large market of e-juice variations. In fact, Malaysia has been known to be the second largest vaping community in the world (Winn, 2015). A local study has shown that 66.7 percent of a sample of 277 perceived that the existence of varieties of e-juice flavours increased satisfaction levels (Elkalmi et al., 2016). Over the years, the range of flavours and tastes from the readily available wide variety of foods in the country, largely shaped by its mutlticultural diversity, played a huge part in enriching the lives of Malaysian people by enabling them to appreciate the cuisine of other cultural communities and also incorporating elements of sensorial delights into their own cuisines to create greater varieties and choices (Perry, 2017). With readily available wide variety of culinary choices, Malaysians are now defined by their obsessive love for foods (Perry, 2017), paving the way for different communities to share in mutually pleasurable experiences of different cuisines (Hooks, 1992), embodying a form of cultural appropriation common in Malaysia (Flowers and Swan, 2012). It may well serve to provide some insights into its significance in this study population.

Based on the data, it is conceivable that having the ability to choose what one specifically desires in terms of e-juice is a motivating factor in continued e-cigarette usage. This finding is consistent with two factors of Glasser's choice theory which was freedom and fun, or "the ability to select a preferred course of action and to have personal enjoyment (Averill, 1973; Inesi, Botti, Dubois, Rucker, \& Galinsky, 2011; Glasser, 1998). In the case of young adults, freedom, fun and autonomy have been reported to be stronger predictors of subjective well being than survival, love and belonging needs (Türkdoğan \& Duru, 2012). Needless to say, there is a high probability that this theme was uncovered because Malaysia possesses the platform where the vaping community is large.

\subsection{Sense of Accomplishment}

The findings highlighted that vapers continued their vaping behaviour due to a sense of accomplishment achieved through customisation and sharing through social media sites. This sense of affirmation and accomplishment was found to be a reinforcing factor in maintaining e-cigarette usage which was also explained by the psychological need to have a sense of achievement in ones' life (Glasser, 1998). These experiences are received as pleasurable to the point of being able to reinforce further ongoing attempts at accomplishing more. Such experiences have been demonstrated especially in young people who engaged in video-games and are subsconsiously encouraged to continue playing, resembling positive reinforcement in "operant" conditioning (Skinner, 1953). An internal reward mechanism is activated as in Bandura's $(1986 ; 2001)$ social cognitive theory which subscribes to a model of emergent interactive agency including neural events.

\subsection{Behavioural Substitution}

Participants in this study acknowledged that vaping can turn into a habit or a substitute to cigarette smoking behaviour, satisfying the oral behaviour of inhaling a substance and then exhaling, revealing the stream of smoke or vapour which grants them a sense of enjoyment in terms of visually perceiving the smoke or vapour.

Habits are learned dispositions to repeat past actions automatically in response to contextual cues that have been associated with their performance (Wood \& Neal, 2007). An example is that of picking up a cigarette immediately following a meal. They are behaviours that tend to be played out at the same location and time, usually without conscious intent (Danner, Aarts \& de Vries, 2008). Such a combination of characteristics, i.e., unconscious behavioural intent; shift of behavioural control from willpower to cues; and reward in the sense of enjoyment serve as reinforcers making existing habits resistant to change.

In terms of behaviour, smoking and vaping are very similar as both require inhalation and exhalation. However, the amount of vapour that can be produced is much higher with an e-cigarette compared to smoke from a cigarette. The visual pleasure may play a significant contribution in maintaining e-cigarette usage as "cloud chasing" events are a major staple in vaping communities (Mosbergen, 2014; Malia, 2016). It can be seen in Table 1, that 9 out of 17 participants were dual users of various durations at the time of interview. This raises the question of whether vaping is an effective smoking cessation method or is it a complement to the oral behaviour. It should also be noted that of these dual-users, most of them have been using e-cigarettes for less than 2 years. This brings about additional questions, mainly: is vaping duration correlated with cigarette smoking reduction? Also, does duration of vaping contribute to reduction in vaping frequency hence leading to vaping cessation?

\subsection{Perceived Low Health Risk}

The prevalence of smoking among adults aged 18 and above in Malaysia is reported by the National Health and Morbidity Survey to be $22.8 \%$, with a higher percentage of $27.7 \%$ in rural areas compared with $20.9 \%$ in urban areas (Institute for Public Health, 2015). Detrimental effects of smoking on health tend to be downplayed by 
smokers (Paretti-Wattel, 2006), possibly due to cognitive dissonance to make it compatible with their smoking habit (Lim et al., 2009).

Findings from this study suggest that participants chose to continue their vaping behaviour because of the perceived decrease in health risk of the e-cigarette compared to cigarettes. The evidence against health effects of e-cigarettes remain inconclusive and possibly relatively positive from the recent statement by the American Cancer Society (2018). In terms of Malaysia, the literature showed that 85 percent of a study's sample was convinced that e-cigarettes are healthier than cigarettes (Wong et al., 2016), consistent with the survival motivation as in Choice Theory (Glasser, 1998). It suggests that Malaysian vapers may only wish to substitute the behaviour instead of going to the next step which is to cease vaping. Findings from this study showed a participant intending to substitute smoking behaviour with vaping. However, this substitution does not seem to address the oral habit of inhaling and blowing out smoke, which according to Rahman, Mohamad, \& Jamshed (2015), is the "chronic nature of smoking". The question that persists, is whether vaping is being used as a cessation method or a substitution method?

\subsection{Financial Savings}

Financial savings were a factor in maintaining e-cigarette usage. This finding was consistent with recent research on financial aspects of vaping in Malaysia which found that 65 percent of their sample perceived vaping to be significantly cheaper than smoking (Wong et al., 2016). This was substantiated by another study which found that 40.8 percent of the sample reported vaping to be cheaper than cigarette smoking (Elkalmi et al., 2016). However, these studies did not conclude that financial savings were also the reason for continued usage of the e-cigarette.

Therefore, there remains a possibility that vaping behaviour among Malaysians may decrease if the price of vaping products were to increase. This is reinforced by a local study which found that participants who disagree with the statement "Smoking e-cigs is relatively cheaper compared to tobacco cigarettes" were significantly attributed to higher intentions to quit usage of e-cigarettes (Wong et al., 2016). They are consistent with two of Choice Theory's factors of behaviour, i.e. survival and freedom. In this case, survival meant saving money so that the resource could be channelled into keeping the body alive, and freedom in a way that saving money can give the individual increased financial freedom.

\subsection{Convenience}

Participants said that vaping is more convenient because they do not need to frequently go to convenience stores to purchase cigarettes as a bottle of e-juice can last much longer than a box of cigarettes. Also, it was expressed that when a person is vaping he does not need to wait for it to finish, as compared to smoking, one feels the need to finish the whole cigarette before moving on to other activities. This grants vapers the sense of freedom that cigarettes did not offer as it forms a barrier to other activities. Freedom in Choice Theory meant having the ability to act and make choices without unreasonable restraints, thereby, satisfying a human psychological need (Glasser, 1998).

\section{Limitations and Improvements for the Future}

- Whilst deeper insights have been gained, the qualitative nature of this study is such that definitive conclusions cannot be made without further studies.

- Future research should further explore the psychological mechanisms that grant pleasure in vapers and smokers alike.

- The sample recruited in this study were mostly university students and young adults ranging from 20 to 30 years old, mostly from similar social economic groups. It was not intentional, but an indication of the age groups who tended to frequent the vape cafes. It suggests the need for studying other groupings involved in vaping. Although research suggests that e-cigarette users typically fall within this age range, there might be a difference in perception and thought process of older populations as well as from different social, educational and working backgrounds in using the product.

- The initial start-up cost raises the question of whether those from lower socioeconomic groups may be less inclined to be vapers.

- There is a possibility that vaping may have replaced tobacco smoking following governmental bans on their use in public places. This may be reflected by the relatively large percentage of just over one third of the sample who reported not having made attempts to stop vaping. An even larger percentage reported having attempted to stop. Greater insights could have been obtained from this group. That, and also given its 
relatively recent usage history, a longitudinal study would be useful to get a better picture such as whether vapers do eventually give up the behaviours completely

\section{Conclusion}

Conventional smoking cessation strategies have primarily involved a combination of behavioural and pharmacological treatment. More recently, e-cigarettes have shown promise for some, but many who switched to e-cigarettes continue with them rather than ceasing entirely. This study set out to explore reasons for continued vaping behaviour in Malaysia. The findings suggest that vaping behaviour amongst young adults could be conceptualised by Choice Theory based on psychosocial needs of survival, achievement, love and belonging, freedom and fun. Such a perspective highlights the role of psychosocial factors that could be considered of importance in informing policy and practices for smoking cessation programmes and activities. Questions for further research have also been identified, including such aspects as, whether the visual pleasure of seeing smoke or vapour exhaled from the mouth contribute to initiation and maintenance of smoking, vaping or even sisha behaviours? If so, what are the psychological mechanisms at play?

\section{References}

Abdullah, A., \& Pedersen, P. B. (2003). Understanding multicultural Malaysia: Delights, puzzles \& irritation. Petaling Jaya: Pearson Malaysia Sdn Bhd.

Abidin, N. Z., Zulkifli, A., \& Abidin, E. Z. (2016). Smoke-Free Legislation in Malaysia: A comprehensive review Smoke-Free Legislation in Malaysia: A comprehensive review. Asia Pacific Environmental and Occupational Health Journal, 2(2), 58-66.

Alpert, H. R., Connolly, G. N., \& Biener, L. (2012). A prospective cohort study challenging the effectiveness of population-based medical intervention for smoking cessation. Tobacco Control, 22(1), 32-37. Retrieved from https://tobaccocontrol.bmj.com/content/22/1/32.short

American Cancer Society. (2018). American Cancer Society Position Statement on Electronic Cigarettes. Retrieved from https://www.cancer.org/healthy/stay-away-from-tobacco/e-cigarette-position-statement.html

ASH. (2014). Over 2 million Britons now regularly use electronic cigarettes. Retrieved May 30, 2018, from http://www.ash.org.uk/media-and-news/press-releases-media-and-news/over-2-million-britons-now-regularl y-use-electronic-cigarettes/

Averill, J, R. (1973). Personal control over aversive stimuli and its relationship to stress. Psychological Bulletin, 80, 286-303.

Ayers, J, W., Ribisi, K. M., \& Brownstein, J. S. (2011). Tracking the rise in popularity of electronic nicotine delivery systems (electronic cigarettes) using search query surveillance. American Journal of Preventive Medicine, 40(4), 448-453. https://doi.org/10.1016/j.amepre.2010.12.007

Bandura, A. (1986). Social foundations of thought and action: A social cognitive theory. Englewood Cliffs, NJ: Prentice-Hall.

Bandura, A. (2001). Social cognitive theory: An agentic perspective. Annual Review of Psychology, 52, 1-26. https://doi.org/10.1146/annurev.psych.52.1.1

Barbeau, A. M., Burda, J., \& Siegel, M. (2013). Perceived efficacy of e-cigarettes versus nicotine replacement therapy among successful e-cigarette users: A qualitative approach. Addiction Science \& Clinical Practice, (8), 5. https://doi.org/10.1186/1940-0640-8-5

Brown, C. J., \& Cheng, J. M. (2014). Electronic cigarettes: Product characterisation and design considerations. Tobacco Control, 23(2), Suppl 2, ii4-ii10. https://doi.org/10.1136/tobaccocontrol-2013-051476

Bush, J., White, M., Kai, J., Rankin, J., \& Bhopal, R. (2003) Understanding influences on smoking in Bangladeshi and Pakistani adults: community based, qualitative study. British Medical Journal, 326(7396), 962-967. https://doi.org/10.1136/bmj.326.7396.962

Chen, I. (2013). FDA summary of adverse events on electronic cigarettes. Nicotine \& Tobacco Research, 15(2), 615- 6. Retrieved from https://www.ncbi.nlm.nih.gov/pubmed/22855883

Danner, U., Aarts, H. \& de Vries, N.K. (2008). Habit vs intention in the prediction of future behaviour: The role of frequency, context stability and mental accessibility of past behaviour. British Journal of Social Psychology, 47(2), 245-265. https://doi.org/10.1348/014466607X230876

Davendralingam, S., \& Erwin, J. K. (2015). E-cigarettes: Facts and legal status. International e-Journal of 
science, medicine and education, 9(3), 10-19.

DeWall, C. N., \& Bushman, B. J. (2011). Social acceptance and rejection: The sweet and the bitter. Current Directions in Psychological Science, 20(4), 256-260. https://doi.org/10.1177/0963721411417545

DeWall, C. N., \& Richman, S. B. (2011). Social exclusion and the desire to reconnect. Social and Personality Psychology Compass, 5(11), 919-932. https://doi.org/10.1111/j.1751-9004.2011.00383.x

Eisenberger, N. I., Lieberman, M. D., \& Williams, K. D. (2003). Does rejection hurt? An fMRI study of social exclusion. Science, 302(5643), 290-292. https://doi.org/10.1126/science.1089134

Elkalmi, R. M., Bhagavathul, A. S., Ya'u, A., Al-Dubai, S. A., Elsayed, T. M., Ahmad, A., \& Mohamed, W. (2016). Familiarity, perception, and reasons for electronic-cigarette experimentation among the general public in Malaysia: Preliminary insight. Journal of Pharmacy \& Bioallied Sciences, 8(3), 240-247. https://doi.org/10.4103/0975-7406.180768

Farsalinos, K. E., Romagna, G., Tsiapras, D., Kyrzopoulos, S., Spyrou, A., \& Voudris, V. (2013). Impact of flavour variability on electronic cigarette use experience: An internet survey. International Journal of Environmental Research and Public Health, 10(12), 7272-7282. https://doi.org/10.3390/ijerph10127272

Flowers, R., \& Swan, E. (2012). Eating the Asian Other? Pedagogies of Food Multiculturalism in Australia. Journal of Multidisciplinary International Studies, 9(2), 1-30.

Foulds, J. Veldheer, S. \& Berg, A. (2011). Electronic cigarettes (e-cigs): Views of aficionados and clinical/public health perspectives. International Journal of Clinical Practice, 65(10), 1037-1042. https://doi.org/10.1111/j.1742-1241.2011.02751.x

Glasser, W. (1998). Choice theory: A new psychology of personal freedom. New York: Harper Collins.

Glesne, C. (2011). Becoming qualitative researchers: An introduction (4th ed.). Boston, Mass: Pearson.

Goniewicz, M. L. ,Lingas, E. O., \& Hajek, P. (2013). Patterns of electronic cigarette use and user beliefs about their safety and benefits: An Internet survey. Drug \& Alcohol Review, 32(2), 133-140. https://doi.org/10.1111/j.1465-3362.2012.00512.x

Gravely, S., Fong, G., Cummings, K., Yan, M., Quah, A., Borland, R., \& Hummel, K. (2014). Awareness, Trial, and Current Use of Electronic Cigarettes in 10 Countries: Findings from the ITC Project. International Journal of Environmental Research and Public Health, 11(11), 11691-11704. https://doi.org/10.3390/ijerph111111691

Hammal, F., \& Finegan, B, A. (2016). Exploring Attitudes of Children 12-17 Years of Age Toward Electronic Cigarettes. Journal of Community Health, 41, 962-968. https://doi.org/10.1007/s10900-016-0178-6

Hillebrandt, H., Sebastian, C. \& Blakemore, S. (2010). Experimentally induced social inclusion influences behavior on trust games. Cognitive Neuroscience, $2(1), \quad 27-33$. https://doi.org/10.1080/17588928.2010.515020

Hofstede, G. (1984). Culture's consequences: International differences in work-related values (2nd ed.). Beverly Hills, CA: Sage.

Hooks, B. (1992). Eating the Other. In B. Hooks (Ed.), Black Looks: Race and representation (pp. 21-39). Boston: South End Press.

Hua, M., Alfi, M., \& Talbot, P. (2013). Health-related effects reported by electronic cigarette users in online forums. Journal of Medical Internet Research, 15(4), e59. https://doi.org/10.2196/jmir.2324

Hughes, J. R., Cummings, K. M., Foulds, J., Shiffman, S., \& West, R. (2012). Effectiveness of nicotine replacement therapy - a rebuttal. Addiction, 107(8), https://doi.org/10.1111/j.1360-0443.2012.03925.x

Inesi, M. E., Botti, S., Dubois, D., Rucker, D. D., \& Galinsky, A. D. (2011). Power and choice: Their dynamic interplay in quenching the thirst for personal control. Psychological Science, 22(8), 1042-1048. https://doi.org/10.1177/0956797611413936

Institute for Public Health. (2015). National Health \& Morbidity Survey: Report on smoking status among Malaysian adults. Institute for Public Health, Ministry of Health Malaysia: Kuala Lumpur.

Kohrman, M. (2007). Depoliticizing tobacco's exceptionality: Male sociality, death and memory-making among Chinese cigarette smokers. The China Journal, 58, 85-109. Retrieved from https://anthropology.stanford.edu/sites/default/files/kohrman_depoliticizing.pdf 
Leary, M. R. (2010). Affiliation, acceptance, and belonging. In S. T. Fiske, D. T. Gilbert, \& G. Lindzey (Eds.), Handbook of Social Psychology (5th ed., Vol. 2, pp. 864-897). New York, NY: Wiley.

Lim, K. H., Sumarni, M. G., Amal, N. M., Hanjeet, K., Wan Rozita, W. M., \& Norhamimah, A. (2009). Tobacco use, knowledge and attitude among Malaysians age 18 and above. Tropical Biomedicine, 26(1), 92-99.

Ling, P. M., \& Glantz, S. A. (2002). Why and how the tobacco industry sells cigarettes to young adults: evidence from industry documents. American Journal of Public Health, 92(6), 908-916.

Malia. J. (2016). Yes, There is Such a Thing as Competitive Vaping. Huffington Post UK Lifestyle. Retrieved from https://www.huffingtonpost.co.uk/jess-melia/competitive-vaping_b_11405304.html?guccounter=1

Maner, J. K., Miller, S. L., Schmidt, N. B., \& Eckel, L. A. (2010). The endocrinology of exclusion: Rejection elicits motivationally tuned changes in progesterone. Psychological Science, 21(4), 581-588. https://doi.org/10.1177/0956797610362676

McQueen, A., Tower, S., \& Sumner, W. (2011). Interviews with "vapers": implications for future research with e-cigarettes. Nicotine \& Tobacco Research, 860-867. https://doi.org/10.1093/ntr/ntr088

Measham, F., O’Brien, K., \& Turnbull, G. (2016). "Skittles \&amp; Red Bull is my favourite flavour": E-cigarettes, smoking, vaping and the changing landscape of nicotine consumption amongst British teenagers - implications for the normalisation debate. Drugs: Education, Prevention and Policy, 7637(Sept), 1-14. https://doi.org/10.1080/09687637.2016.1178708

Moore, D., Aveyard, P., Connock, M., Wang, D., Fry-Smith, A., \& Barton, P. (2009). Effectiveness and safety of nicotine replacement therapy assisted reduction to stop smoking: systematic review and meta-analysis. British Medical Journal, 338, b1024. https://doi.org/10.1136/bmj.b1024

Mosbergen, D. (2014). This Man Is An Athlete In The Sport Of 'Cloud Chasing'. The Huffington Post (5 August 2014). Retrieved from https://www.revolvy.com/page/Cloud\%252Dchasing-\%28electronic-cigarette\%29

Mottern, R. (2008). Choice Theory as a Model of Adult Development. International Journal of Reality Therapy, $27(2), 35-40$.

Nik Mohamad, H., \& Jamshed, S. (2015). Safety and effectiveness of electronic cigarette as vapers perspective: A qualitative approach. International Medical Journal, 22(5), 362-366.

Orr, K. K., \& Asal, N. J. (2014). Efficacy of electronic cigarettes for smoking cessation. Annals of Pharmacotherapy, 48(11), 1502-1506. https://doi.org/10.1177/1060028014547076

Palazzolo, D. L. (2013). Electronic Cigarettes and Vaping: A New Challenge in Clinical Medicine and Public Health. A Literature Review. Front Public Health, 1 (Nov), 56. https://doi.org/10.3389/fpubh.2013.00056

Paretti-Watel, P. (2006). Cognitive dissonance and risk denial: The case of cannabis use in adolescents. Journal of Behavioural and Experimental Economics, 35(6), 1032-1049.

Paul, C. L., Ross, S., Bryant, J., Hill, W., Bonevski, B., \& Keevy, N. (2010). The social context of smoking: A qualitative study comparing smokers of high versus low socioeconomic position. BMC Public Health, 10, 211. https://doi.org/10.1186/1471-2458-10-211

Pepper, J, K., \& Brewer, N. T. (2014). Electronic nicotine delivery system (electronic cigarette) awareness, use, reactions and beliefs: A systematic review Jessica. Tobacco Control, 23(5), 375-384. https://doi.org/10.1136/tobaccocontrol-2013-051122

Perry, M. S. (2017). Feasting on culture and identity: Food functions in a multicultural and transcultural Malaysia. The Southeast Asian Journal of English Language Studies, 23(4), 184-199. Retrieved from http://ejournal.ukm.my/31/article/view/21729/7203

Rafter, D. (2008). Smokin' hot. Specialty Retail Report. 2008 Fall. Retrieved from: http://www.specialtyretail.com/2008/fall/retailer_profiles/smoking_hot_cover_story 5

Rahman, A. U., Mohamad, M. H., \& Jamshed, S. (2015). Safety and Effectiveness of Electronic Cigarette as Vapers Perspective: A Qualitative Approach. International Medical Journal, 22(5), 362-366.

Skinner, B. F. (1953). Science and Human Behavior. New York: MacMillan.

Song, A. V., \& Ling, P. M. (2011). Social Smoking Among Young Adults: Investigation of Intentions and Attempts to Quit. American Journal of Public Health, 101(7), 1291-1296. https://doi.org/10.2105/AJPH.2010.300012 
Speziale, H. S., Streubert, H. J., \& Carpenter, D. R. (2011). Qualitative research in nursing: Advancing the humanistic imperative. Lippincott Williams \& Wilkins.

Türkdoğan, T., \& Duru, E. (2012). The role of basic needs fulfilment in predictions of subjeective well-being among university students. Educational Sciences: Theory \& Practice, 12(4), 2440-2446.

Vansickel, A. R., Cobb, C. O., Weaver, M. F., \& Eissenberg, T. E. (2010). A clinical laboratory model for evaluating the acute effects of electronic "cigarettes": Nicotine delivery profile and cardiovas- cular and subjective effects. Cancer Epidemiology Biomarkers \& Prevention, 19, 1945-1953. https://doi.org/10.1158/1055-9965.EPI-10-0288

Wagener, T. L., Siegel, M., \& Borrelli, B. (2012). Electronic cigarettes: achieving a balanced perspective. Addiction, 107(9), 1545-1548. https://doi.org/10.1111/j.1360-0443.2012.03826.x

Williams, K. D., Cheung, C. K. T., \& Choi, W. (2000). Cyberostracism: Effects of being ignored over the $\begin{array}{lllll}\text { Internet. Journal of Personality and Social Psychology, 79, 748-762. } & \text {. }\end{array}$ https://doi.org/10.1037/0022-3514.79.5.748

Winn, P. (2015). Malaysia is now Asia's vaping wonderland (15 November 2015). Retrieved from http://theweek.com/articles/587910/malaysia-now-asias-vaping-wonderland

Wong, L. P, Shakir, S. M., Alias, H., Aghamohammadi, N., \& Hoe, V. C. (2016). Reasons for Using Electronic Cigarettes and Intentions to Quit Among Electronic Cigarette Users in Malaysia. Journal of Community Health, 41(6), 1101-1109. Retrieved from https://link.springer.com/article/10.1007/s10900-016-0196-4

Wood, W., \& Neal, D.T. (2007). A new look at habits and habit-goal interface. Psychological Review, 114(4), 843-863. https://doi.org/10.1037/0033-295X.114.4.843

Yeh, J. S., Bullen, C., \& Glantz, S. A. (2016). E-cigarettes and smoking cessation. New England Journal of Medicine, 374(22), 2172-2174. https://doi.org/10.1056/NEJMclde1602420

\section{Copyrights}

Copyright for this article is retained by the author(s), with first publication rights granted to the journal.

This is an open-access article distributed under the terms and conditions of the Creative Commons Attribution license (http://creativecommons.org/licenses/by/4.0/). 